\title{
The Novel Current Control for Virtual Synchronous Generator
}

\author{
Atsushi Umemura, Rion Takahashi, Junji Tamura \\ Department of Electrical and Electronic Engineering, Kitami Institute of Technology, Kitami, Japan \\ Email: umemura@mail.kitami-it.ac.jp
}

How to cite this paper: Umemura, A. Takahashi, R. and Tamura, J. (2020) The Novel Current Control for Virtual Synchronous Generator Journal of Power and Energy Engineering, 8, 78-89. https://doi.org/10.4236/ipee.2020.82004

Received: January 12, 2020

Accepted: February 25, 2020

Published: February 28, 2020

Copyright (อ 2020 by author(s) and Scientific Research Publishing Inc. This work is licensed under the Creative Commons Attribution International License (CC BY 4.0).

http://creativecommons.org/licenses/by/4.0/ (c) (i) Open Access

\begin{abstract}
In recent years, power generation using renewable energy sources has been developed as a solution to the global warming problem. Among these power generation methods, wind power generation is increasing. However, as the penetration level of wind power generation increases, the low inertia and lack of synchronous power characteristics of the penetrated power system can have a significant impact on the transient stability of the grid. The virtual synchronous generator provides the ability of virtual inertia and synchronous power to interconnected inverters. The interconnected inverter with the virtual synchronous generator ability uses, in general, PI control based current controller. This paper proposes a new current-control method and compares it with conventional methods. The proposed current control is a method that follows virtual synchronous generator model that changes every moment by solving the discrete-time linear quadratic optimal control problem for each sampling time interval. The new method follows the conventional method, and therefore the reactive power fluctuation can be suppressed and the interconnected inverter will be downsized.
\end{abstract}

\section{Keywords}

Wind Energy Generation, State Feedback, Electric Current Control, Linearization Techniques, Discrete Time Model Following Control, Virtual Synchronous Generator

\section{Introduction}

Currently, the world faces global warming challenges due mainly to fossil fuel power generation [1]. The power generation using renewable energy has been developed as a solution to global warming challenges. Among renewable energy power sources, wind power has been attracting more attention. Wind power 
generation has the advantage of low power generation costs and high conversion efficiency compared with other renewable sources. In most of the development new megawatt-scale wind turbines is of variable speed using either a permanent magnet synchronous generator or a doubly fed induction generator. Back-to-back converters for variable speed wind turbines are installed between the wind generator and the grid [2]. The grid-connected inverters for variable speed wind turbines have a small output power limit, no damping, no synchronous power, and no inertia. Typically, a grid system has synchronous generators with synchronizing power and inertia. They are able to provide active power and reactive power dynamically to keep the grid voltage and frequency constant.

The virtual synchronous generator is a method that provides virtual inertia and synchronous power to interconnected inverters [3]. Virtual inertia can be established in a distributed generator, for example, a renewable energy source using a power electronics inverter and a converter with a current-control system. This method is called a virtual synchronous generator or an asynchronous virtual machine. In 2007, the Virtual Synchronous Generator research group focused on a current-reference emulated inertia provided by a phase lock loop (PLL) for a rotating frame for the dq control of an inverter.

The virtual synchronous generator of the Institute of Electrical Power Eng. (IEPE) at Clausthal University of Technology in Germany is based on a simplified synchronous generator model. A reference current (voltage) of this method is provided from the grid voltage (current). This method helps to improve the frequency stabilization in short time. Furthermore, this method allows voltage source converters to be connected to a weak grid system by the PLL synchronizing technique.

A study of a wind diesel system with a short-term energy storage system (ESS) controlled as a virtual inertia and a virtual synchronous generator was presented in [4]. Their ESS controller as a virtual inertia can enhance the dynamic frequency stability of a small scale grid under fluctuating renewable energy and load fluctuations. The optimized variable inertia is introduced in the virtual inertia method which can improve the grid frequency response with lower power compared to the conventional fixed virtual inertia method.

The study in [5] demonstrated a model for a grid-following and grid-forming virtual inertia converter for a low inertia grid system. A grid-following virtual inertia converter is controlled to output active power proportional to the frequency deviation and rate of change of frequency estimated by a PLL. However, the grid-forming virtual inertia converter uses a voltage source connected to the grid through an LC filter of which the output voltage is based on the angle which is the function of power in feed of the virtual inertia converter.

Most of them use PI control scheme in the rotating frame for current (voltage) control of the converter. We propose a model-following control for the interconnected inverter [6] [7] [8]. The model-following controlled inverter can follow the reference model more accurately than the conventional method. The ba- 
sic configuration is to output power from the voltage inverter connected to the grid through a filter, in a similar way to a grid-forming virtual inertia converter. The method presented in this paper follows reference current by instantaneous control with emulating not only inertia but also synchronous power based on the simple synchronous generator model. There is no control delay resulting from PLL, because PLL is not required for instantaneous value control.

This paper is organized as follows: Chapter 2 describes a discrete-time model-following control (DMFC) system consisting of the virtual synchronous generator model, an inverter grid model and a state feedback gain. The simulation results and discussions of the proposed controller are provided in Chapter 3. Finally, Chapter 4 describes the conclusion.

\section{Proposed Novel Current Controller}

\subsection{Discrete Time Model Following Controller}

This chapter describes the discrete-time model following control system.

Figure 1 shows a grid connected inverter with an LCL filter for a wind generator.

This inverter system comprises a wind turbine, a three-phase diode rectifier, a three-phase full-bridge PWM inverter, and an LCL filter installed between the inverter and the grid voltage with the equivalent grid system impedance.

Figure 2 shows a diagram of the discrete time model following system. The system shown in Figure 2 is a hybrid system consisting of the continuous-time plant system, the discrete time virtual synchronous generator model, and the discrete-time state feedback gain.

The state feedback gain is derived next. The extended system equation used to derive the state feedback gain is given by

$$
\begin{aligned}
& x_{k+1}=A x_{k}+B v_{i k} \\
& \varepsilon_{k}=C x_{k}
\end{aligned}
$$

Commonly, models are not always reachable. Thus, the model space is often broken down into reachable model space and non-reachable model space. Equation (1) can be rewritten as follows:

$$
\left[\begin{array}{c}
x_{1 k+1} \\
x_{2 k+1}
\end{array}\right]=\left[\begin{array}{cc}
A_{11} & A_{12} \\
0 & A_{22}
\end{array}\right]\left[\begin{array}{c}
x_{1 k} \\
X_{2 k}
\end{array}\right]+\left[\begin{array}{c}
B_{1} \\
0
\end{array}\right] v_{i k}
$$

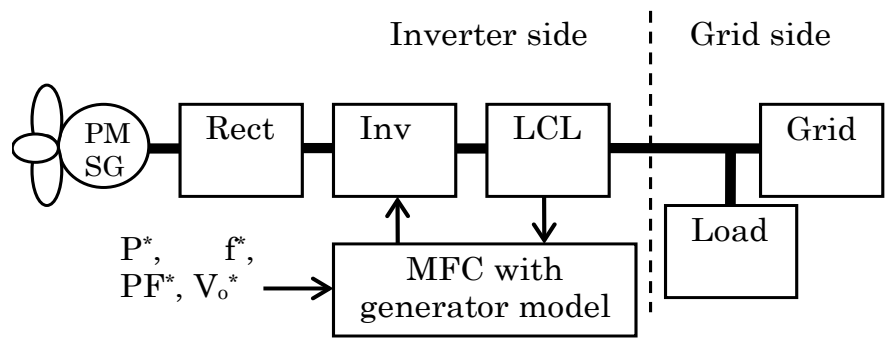

Figure 1. Wind turbine system with grid connected inverter. 


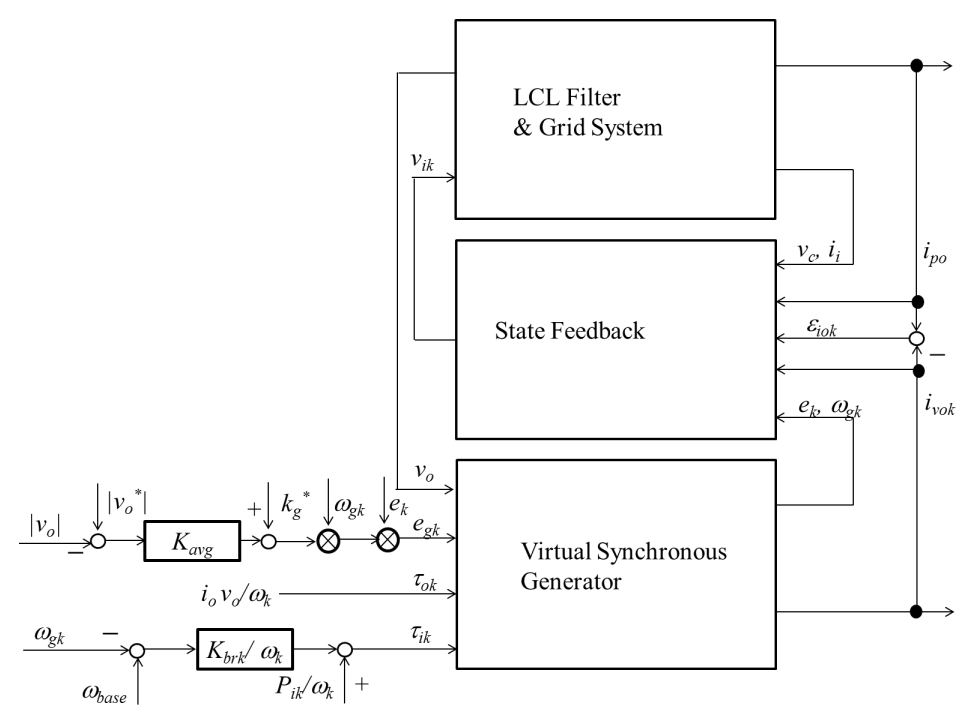

Figure 2. Discreat-time model following controller with virtual synchronous generator.

where the state vector with a reachable space $x_{1 k}=\left[x_{p 1 k}^{\mathrm{T}} e_{k}^{\mathrm{T}} \mathrm{T}_{\text {vok }}^{\mathrm{T}}\right]^{\mathrm{T}}$, a state vector with a non-reachable space $x_{2 k}=\left[x_{c 2 k}^{\mathrm{T}} v_{k}^{\mathrm{T}}\right]^{\mathrm{T}}$; a plant state vector $x_{p 1 k}=\left[i_{p o k}^{\mathrm{T}} v_{c k}^{\mathrm{T}} i_{i k}^{\mathrm{T}}\right]^{\mathrm{T}}$; the output current vector of the virtual synchronous model $i_{\text {vok }}$; the LCL filter output current vector $i_{p o k}$; the capacitor voltage vector of the LCL filter $V_{c k}$; the input current vector of the LCL filter $i_{i k}$; a non-reachable state vector of the virtual synchronous model $x_{c 2 k}=\left[w_{g k} e_{k}^{T}\right]^{\mathrm{T}}$; the rotation speed of a virtual synchronous generator $\omega_{g k}$; the unit vector of the no-load induced voltage $e_{k}$; and the input voltage vector of LCL filter $v_{i k} . C_{p d 1}$ is defined by $i_{p o k}=C_{p d 1} X_{p 1 k}$,

$$
\begin{aligned}
& A_{11}=\left[\begin{array}{cc}
A_{p d 11} & 0 \\
A_{c 101} & A_{c 11}
\end{array}\right], A_{12}=\left[\begin{array}{cc}
0 & A_{p d 12} \\
A_{c 12} & A_{c 102}
\end{array}\right], B_{1}=\left[\begin{array}{c}
B_{p d 1} \\
0
\end{array}\right], \\
& A_{22}=\left[\begin{array}{cc}
A_{c 22}\left(\omega_{g k}\right) & 0 \\
0 & A_{p v g}
\end{array}\right], A_{c 101}=\left[\begin{array}{c}
C_{p d 1} \\
-B_{v i} C_{o 1}
\end{array}\right], A_{c 102}=\left[\begin{array}{c}
0 \\
-B_{v i} C_{o 2}
\end{array}\right] \text {, } \\
& A_{c 11}=\left[\begin{array}{cc}
-A_{\varepsilon} & -1 \\
0 & A_{v i}
\end{array}\right], A_{c 12}=\left[\begin{array}{ccc}
0 & 0 & \\
0 & B_{v i} C_{v e}\left(\omega_{g k}\right. & v_{o k}
\end{array}\right]
\end{aligned}
$$

The quadratic evaluation function is given by:

$$
J=\sum_{k=0}^{\infty}\left(\left\|\varepsilon_{k}\right\|_{Q}^{2}+\left\|v_{i k}\right\|_{R}^{2}\right)
$$

In this case, the optimal input is given by:

$$
v_{i k}=-\left(R+B^{\mathrm{T}} P B\right)^{-1} B^{\mathrm{T}} P A x_{k}
$$

where $P$ is a solution of the following Riccati equation.

$$
P=A^{\mathrm{T}} P A+C^{\mathrm{T}} Q C-A^{\mathrm{T}} P B\left(R+B^{\mathrm{T}} P B\right)^{-1} B^{\mathrm{T}} P A
$$


Matrix $P$ is divided into four sub-matrixes.

$$
P=\left[\begin{array}{ll}
P_{11} & P_{12} \\
P_{12}^{T} & P_{22}
\end{array}\right]
$$

Because the lower submatrix of matrix $B$ is a zero-matrix, the optimal input is as follows:

$$
v_{i k}=-\left(R+B_{1}^{\mathrm{T}} P_{11} B_{1}\right)^{-1} B_{1}^{\mathrm{T}}\left[P_{11} A_{11} \quad P_{12} A_{22}\right] x_{k}
$$

It should be noted that the above equation is used for only $P_{11}$ and $P_{12}$.

Thus, there is a solution that satisfies the following:

$$
P_{11}=A_{11}^{\mathrm{T}} P_{11} A_{11}+C_{1}^{\mathrm{T}} Q C_{1}-A_{11}^{\mathrm{T}} P_{11} B_{1}\left(R+B_{1}^{\mathrm{T}} P_{11} B_{1}\right)^{-1} B_{1}^{\mathrm{T}} P_{11} A_{11}
$$

$P_{12}$ can also be obtained from the following equation.

$$
P_{12}=A_{11}^{\mathrm{T}} P_{11} A_{12}+A_{11}^{\mathrm{T}} P_{12} A_{22}-A_{11}^{\mathrm{T}} P_{11} B_{1}\left(R+B_{1}^{\mathrm{T}} P_{11} B_{1}\right)^{-1} B_{1}^{\mathrm{T}}\left(P_{11} A_{12}+P_{12} A_{22}\right)
$$

The virtual synchronous generator model is nonlinear, and the rotor speed of the virtual synchronous generator model changes with time. Therefore, this optimal input may be a derivative in each discrete-time interval.

\subsection{Grid Connected Inverter}

The plant system shown in Figure 3 shows a block diagram of the wind turbine system with discrete-time model following controller.

In this paper, the three phase circuits are assumed to be symmetrical. Thus, the plant system can be shown using only a single phase. An inverter with the wind generator is simulated with an ideal voltage source.

A continuous-time plant is composed of an inverter LCL filter, an impedance of the grid system, and a voltage source, which simulates the power system.

The plant system is described as follows:

$$
\begin{gathered}
\frac{d}{d t} \dot{i}_{p o}+T_{g d}^{-1} i_{p o}=l_{g d}^{-1}\left(v_{o}-v_{g}\right) \\
\frac{d}{d t} \dot{i}_{p o}+T_{2}^{-1} i_{p o}=l_{2}^{-1}\left(v_{c}-v_{o}\right) \\
\frac{d}{d t} \dot{i}_{i}+T_{1}^{-1} i_{i}=l_{1}^{-1}\left(v_{i}-v_{c}\right) \\
\frac{d}{d t} \dot{v}_{c}=c_{Y}^{-1}\left(i_{i}-i_{p o}\right)
\end{gathered}
$$

where $i_{p o}$ (instantaneous current [A] divided by the base current [A]) is the output current vector of the LCL filter composed of a zero-sequence current, a

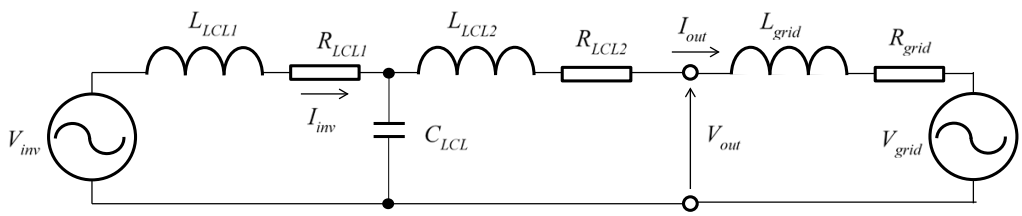

Figure 3. Single phase circuit of the three phase grid connected inverter with LCL filter. 
positive-sequence current and a negative-sequence current; $i_{i}$ is the input current vector of the LCL filter; $v_{c}$ (instantaneous voltage $[\mathrm{V}]$ divided by the base voltage $[\mathrm{V}])$ is a star-connected capacitor voltage vector of the LCL-filter; $V_{i}$ is a filter input voltage vector; $V_{g}$ is the voltage vector of the equipment grid voltage; and $\mathcal{c}_{Y}$ (capacitor [F] multiplied by the base capacitance $[\mathrm{F}]$ ) is the capacitor matrix of the three phases, which are assumed to be symmetrical. Let $l_{1}$ (inductance $[\mathrm{H}]$ divided by the base inductance $[\mathrm{H}]$ ) be the inductance matrix in the filter input side and $T_{1}$ be the time-constant matrix. In addition, $l_{g d}$ is the inductance matrix of the equivalent grid system, and $T_{g d}$ is the time constant matrix.

Combining Equations (11) and (12) gives the following equation.

$$
\left(l_{g d}+l_{2}\right) \frac{d}{d t} i_{p o}+\left(l_{g d} T_{g d}^{-1}+l_{2} T_{2}^{-1}\right) i_{p o}=\left(v_{c}-v_{g}\right)
$$

The grid voltage vector $v_{g}$ is given as follows:

$$
\begin{gathered}
v_{g}=\left|v_{g}\right| v \\
\frac{d}{d t} \dot{v}=\omega_{\text {base }} S_{\alpha \beta} v
\end{gathered}
$$

where $v$ is the unit vector of the grid voltage. The grid voltage magnitude $\left|v_{g}\right|$ is constant. $\omega_{\text {base }}$ is the nominal grid frequency and $S_{\alpha \beta}$ is the following skew matrix.

$$
S_{\alpha \beta}=\left[\begin{array}{ccc}
1 & 0 & 0 \\
0 & 0 & -1 \\
0 & 1 & 0
\end{array}\right]
$$

By assuming that $V_{i}$ and $V_{g}$ are constant during the time interval $T_{s}$ [sec], and $V_{i k}$ and $V_{g k}$ are given, the discrete-time system is derived using Equations (13)-(17) as follows:

$$
\begin{gathered}
i_{p o k+1}=A_{p i o} i_{p o k}+B_{p i o}\left(v_{c k}-v_{g k}\right) \\
i_{i k+1}=A_{p i i} i_{i k}+B_{p i i}\left(v_{i k}-v_{c k}\right) \\
v_{c k+1}=v_{c k}+B_{p v c}\left(i_{i k}-i_{p o k}\right) \\
v_{k+1}=A_{p v g} v_{k} \\
v_{g k}=C_{p v g} v_{k}
\end{gathered}
$$

The plant system equation is as follows:

$$
\left[\begin{array}{c}
X_{p 1 k+1} \\
V_{k+1}
\end{array}\right]=\left[\begin{array}{cc}
A_{p d 11} & A_{p d 12} \\
0 & A_{p v g}
\end{array}\right]\left[\begin{array}{c}
X_{p 1 k} \\
v_{k}
\end{array}\right]+\left[\begin{array}{c}
B_{p d 1} \\
0
\end{array}\right] v_{i k}
$$

where; the plant system state vector $x_{p 1 k}=\left[i_{p o k}^{\mathrm{T}} v_{c k}^{\mathrm{T}} i_{i k}^{\mathrm{T}}\right]^{\mathrm{T}}$, and the filter input voltage vector $v_{i k}$ is the plant system input vector.

\subsection{Virtual Synchronous Generator Model}

The equation of the motion of the virtual synchronous generator is given below: 


$$
\frac{\mathrm{d}}{\mathrm{d} t} \omega_{g}^{2}+2 T_{g}^{-1} \omega_{g}^{2}=2 \omega_{\text {base }}^{2} M_{g}^{-1}\left(P_{i}-P_{o}\right)
$$

where $M_{g}[\mathrm{~s}]$ is the virtual synchronous generatorinertia constant (twice the stored energy constant, $\mathrm{H}), T_{g}[\mathrm{~s}]$ isa mechanical time constant, $\omega_{g}[\mathrm{rad} / \mathrm{s}]$ is the rotor speed, $P_{i}[\mathrm{pu}]$ is the input power, $P_{o}[\mathrm{pu}]$ is the output power, and $\omega_{\text {base }}[\mathrm{rad} / \mathrm{s}]$ is the rated rotor speed. Since the virtual synchronous generator is assumed to have two poles, the rated rotation speed is equal to the rated frequency of the grid system.

If the rotor speed is $\omega\left(=\omega_{g} / \omega_{\text {base }}\right)[\mathrm{pu}]$, the input torque $\tau_{i}[\mathrm{pu}]$ (the output torque $\tau_{o}[\mathrm{pu}]$ ) becomes $\tau_{i}=P_{i} / \omega\left(\tau_{o}=P_{o} / \omega\right)$, so that the Equation (25) becomes as follows.

$$
\frac{\mathrm{d}}{\mathrm{d} t} \omega_{g}+T_{g}^{-1} \omega_{g}=\omega_{\text {base }} M_{g}^{-1}\left(\tau_{i}-\tau_{o}\right)
$$

The power input is composed of a reference output power and a speed governor component, as shown below:

$$
P_{i}=P_{o}^{*}+K_{\text {gov }}\left(\omega_{\text {base }}-\omega_{g}\right)
$$

where $K_{g o v}$ is the governor gain, and $P_{o}^{*}$ is the reference of the output power.

The equation of the electrical circuit of the virtual synchronous generator is given as follows:

$$
\frac{d}{d t} i_{v o}+T_{v o}^{-1} i_{v o}=l_{g}^{-1}\left(e_{g}-v_{o}\right)
$$

where $T_{v o}[\mathrm{~s}]$ is the virtual synchronous generator electrical time constant matrix, $I_{g}$ is the synchronous inductance matrix, $i_{v o}$ is the output current vector of the virtual synchronous generator, $V_{o}$ is the output voltage vector, and $e_{g}$ is the no-load induced voltage vector.

The voltage vector $e_{g}$ is given as follows:

$$
\begin{array}{r}
e_{g}=\left|e_{g}\right| e \\
\frac{d}{d t} \dot{e}=\omega_{g} S_{\alpha \beta} e
\end{array}
$$

where $e$ is the unit vector of the no-load induced voltage. The no-load induced voltage magnitude $\left|e_{g}\right|$ is a time-variant value.

The proportional output voltage regulator gives the no-load induced voltage magnitude $\left|e_{g}\right|$ as:

$$
\left|e_{g}\right|=\left(\left|e_{g}^{*}\right|+K_{\text {avg }}\left(\left|v_{o}^{*}\right|-\left|v_{o}\right|\right)\right) \omega
$$

where $\left|e_{g}^{*}\right|[\mathrm{pu}]$ is the reference value of the no-load induced voltage. $\left|v_{o}^{*}\right|[\mathrm{pu}]$ is reference value of the output voltage. $K_{\text {arg }}$ is the proportional gain of the voltage regulator.

The output voltage $v_{o}$ can be obtained as follows by subtracting Equation (11) and Equation (12).

$$
\left(l_{2}^{-1}+l_{g}^{-1}\right) v_{o}=-\left(T_{2}^{-1}-T_{g}^{-1}\right) i_{p o}+l_{2}^{-1} v_{c}+l_{g}^{-1} v_{g}
$$

The above equation is replaced by the following discrete-time matrix equation.

$$
v_{o k}=\left[\begin{array}{ll}
C_{o 1} & C_{o 2}
\end{array}\right]\left[\begin{array}{ll}
x_{p 1 k}^{\mathrm{T}} & v_{g k}^{\mathrm{T}}
\end{array}\right]^{\mathrm{T}}
$$


If $P_{o}$ and $P_{i}$ take constant values of $P_{o k}$ and $P_{i k}$ during the time interval $T_{s}[\mathrm{~s}]$, the discrete-time system is derived using the Equation (26), (28), (29) and (30), as follows:

$$
\begin{gathered}
\omega_{g k+1}=A_{v w} \omega_{g k}+B_{v w}\left(\tau_{i k}-\tau_{o k}\right) \\
i_{v o k+1}=A_{v i} i_{v o k}+B_{v i}\left(e_{g k}-v_{o k}\right) \\
e_{k+1}=A_{v e}\left(\omega_{g k}\right) e_{k} \\
e_{g k}=C_{v e}\left(\begin{array}{ll}
\omega_{g k} & \left.v_{o k}\right) e_{k}
\end{array}\right.
\end{gathered}
$$

\section{Simulation Result}

\subsection{PI Current Controller}

In this chapter, a current controlled inverter using a rotating frame for a dq transformation and applied by the provided virtual synchronous generator model, is described.

Figure 4 shows a diagram of the discrete-time PI current control system. The control system is composed of a plant system, a virtual synchronous generator model, and a PI controller using a dq transformation.

The system equation of the discrete-time PI controller is given below.

$$
\begin{gathered}
x_{c k+1}=A_{P I} X_{c k}+B_{P I}\left(i_{v o k}^{d q}-i_{p o k}^{d q}\right) \\
v_{i k}^{d q}=C_{P I} X_{c k}+D_{P I}\left(i_{v o k}^{d q}-i_{p o k}^{d q}\right)
\end{gathered}
$$

where $v_{i k}^{d q}$ is the $d q$-transformed $V_{i k}$ and $i_{\text {vok }}^{d q}$ and $i_{p o k}^{d q}$ are the $d q$-transformed $i_{\text {vok }}$ and, $i_{p o k}$.

$$
A_{P I}=\left[\begin{array}{ll}
1 & 0 \\
0 & 1
\end{array}\right], B_{P I}=\left[\begin{array}{l}
1 \\
0
\end{array}\right], C_{P I}=\left[\begin{array}{ll}
K I & 1
\end{array}\right], D_{P I}=[K P]
$$

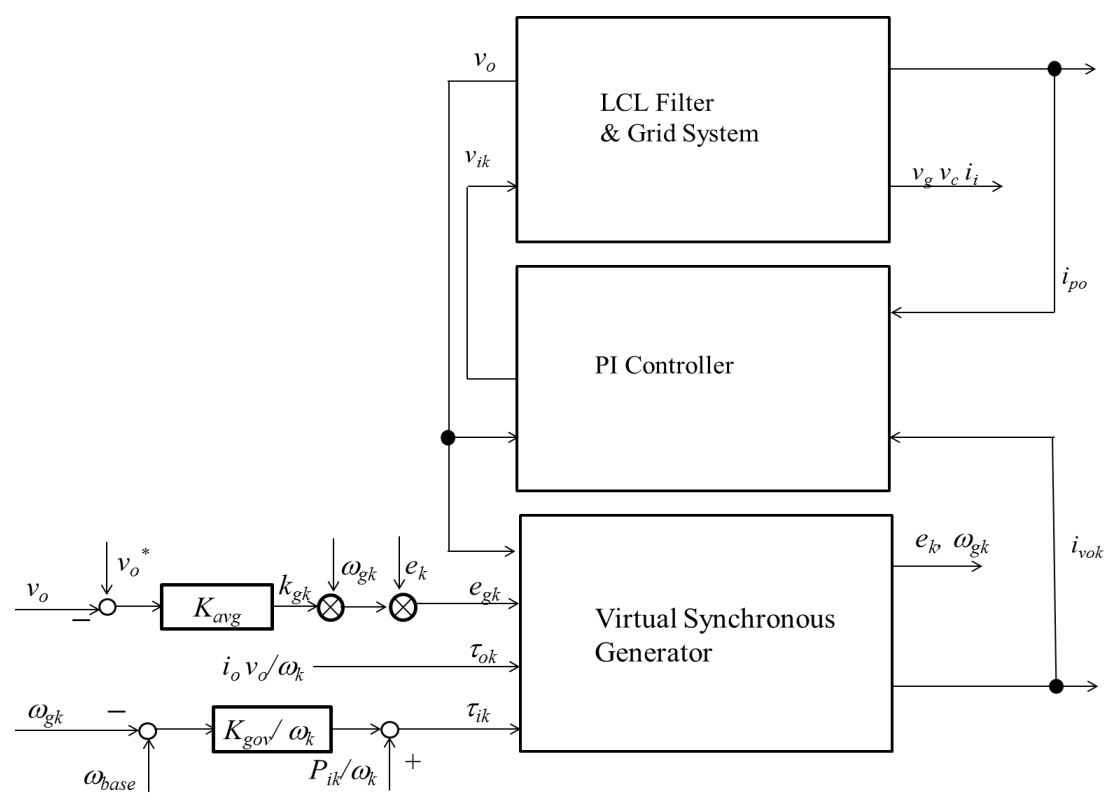

Figure 4. PI current control with the virtual synchronous generator model. 
The PI controller has the proportional gain $K P$ and integral gain $K I$. The PI controller gains are obtained using a limited sensitivity method.

\subsection{Transient Response}

In this section, we compare the responses between the PI control and the proposed method when the output power reference is changed in steps.

In wind power generation, the wind power changes every moment according to the variable wind speed. Assuming the worst case that, the initial output power reference is $1[\mathrm{pu}]$, steps down to $0[\mathrm{pu}]$ at $4[\mathrm{~s}]$, and then steps up to $1[\mathrm{pu}]$ at $5[\mathrm{~s}]$.

The virtual synchronous generator has a synchronous impedance: $2.0[\mathrm{pu}]$, $M_{g}: 3.5$ [s] and $T_{g}: M_{g} / 0.01$ [s]; $K_{g o r}: 1 / 0.05 \omega_{\text {base }} K_{\text {avg }}: 0.5 ; v_{o}^{*}: 1.06 ;$ LCL filter reactance of the converter side $0.024[\mathrm{pu}]$ and of the grid side 0.044 [pu]; a loss resistor $0.001[\mathrm{pu}]$; a cutoff frequency $10.2 \omega_{\text {base }}$ the infinite grid side impedance 0.3 [pu] (self-capacity base).

Both controllers use the same virtual synchronous generator model. When the output power reference changes, the output power oscillates according to the virtual synchronous generator model (Figure 5(b), Figure 6(b)). The inertia of the virtual synchronous generator also suppresses the slowdown of the rotor speed (Figure 5(a), Figure 6(a)).

Figure 5(d) is compared to Figure 6(d). The proposed method has only a steady vibration of less than $0.6 \%$, however it is sufficient for following the virtual generator model. Furthermore, the conventional method has a transient fluctuation with a max peak of $25 \%$ or less.

The proposed method can output the virtual synchronous generator current more accurately.

Both control methods have almost the same active power, and can follow the virtual synchronous generator model accurately enough (Figure 5(b), Figure 6(b)). In the conventional method, the fluctuation of the reactive power is larger than that of the proposed method (Figure 5(c), Figure 6(c)), because of the following error in the current.

The internal phase angle delta in the proposed controller is within the range of 0 to 30 [deg] (Figure 5(e)). However, the internal phase angle exceeds 45 [deg] in the conventional method (Figure 6(f)). Therefore, it can be said the proposed method is more stable than the conventional method. As a result, both control methods can follow the active power of the virtual synchronous generator model accurately enough. However, conventional method has large fluctuations in the reactive power response. On the other hand, proposed method does not require additional power, so that capacity of the converter can be reduced and the stability of the virtual synchronous generator is superior to the conventional one.

\section{Conclusions}

We proposed a discrete time model following control for the current control of a 


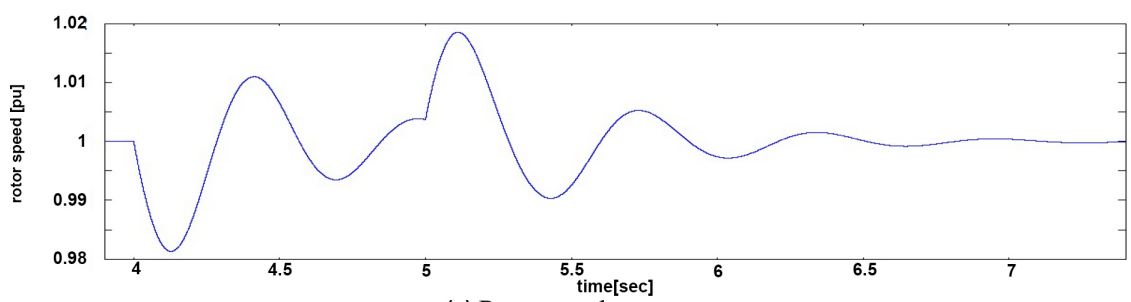

(a) Rotor speed

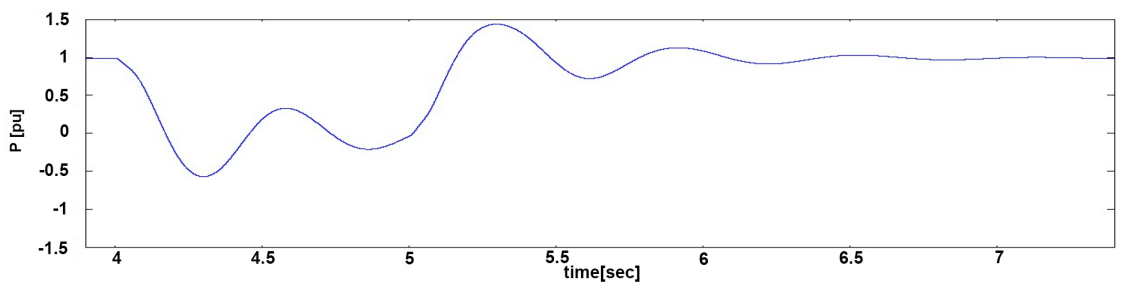

(b) Output power

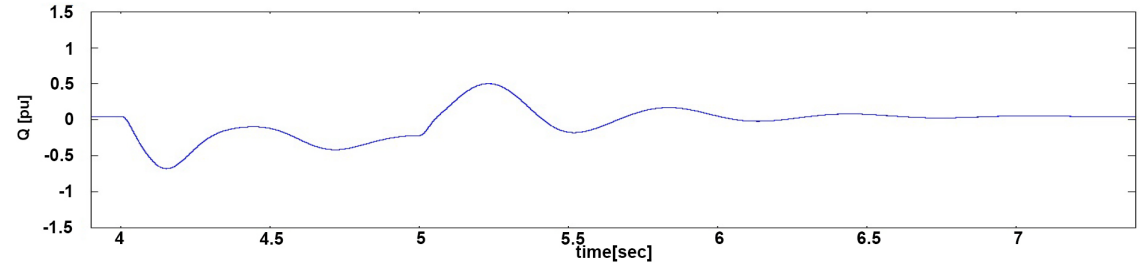

(c) Output reactive power

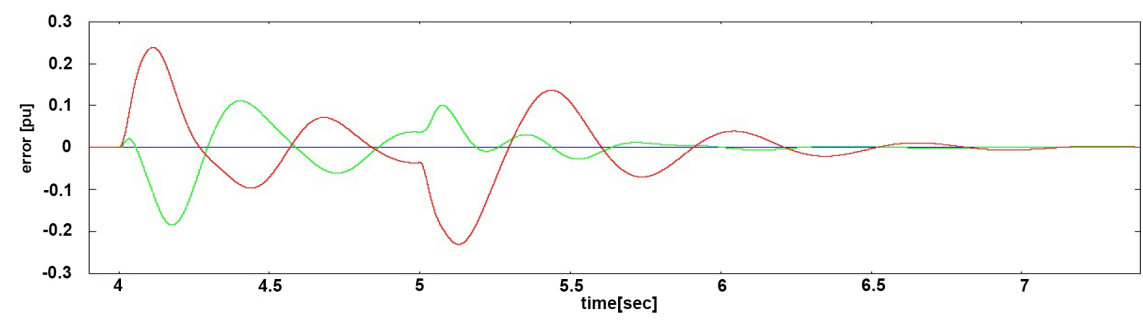

(d) Output current error (blue line: zero sequence current, green line: positive sequence current, red line: negative sequence current)

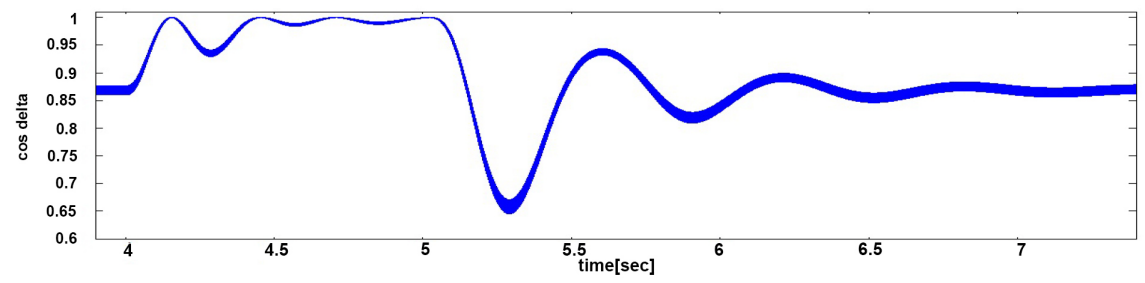

(e) Cosine of internal phase angle

Figure 5. Transient response of the PI currrent controller.

virtual synchronous generator. In this paper, it was shown that a discrete-time model-following control can be derived for each sampling time interval and applied to control in actual case. The proposed method is compared with the conventional PI control method. The proposed method always follows the virtual synchronous generator model more accurately than the conventional method. As a result, the fluctuation of reactive power is suppressed, which can help downsize the capacity of the device. The fluctuation of the internal phase angle of the virtual synchronous generator model can be reduced. Therefore, the 

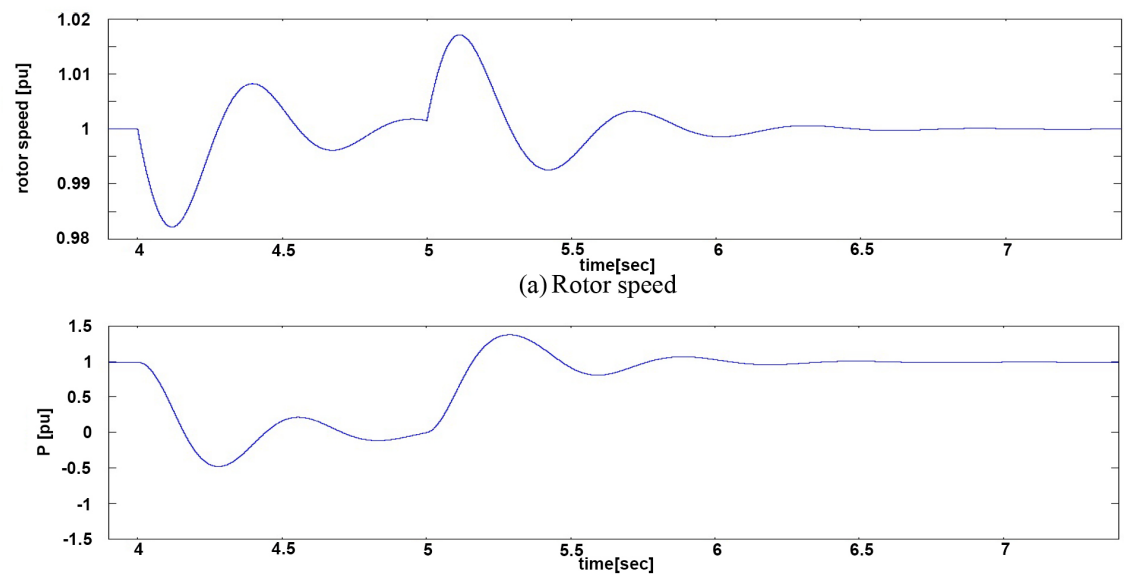

(b) Output power

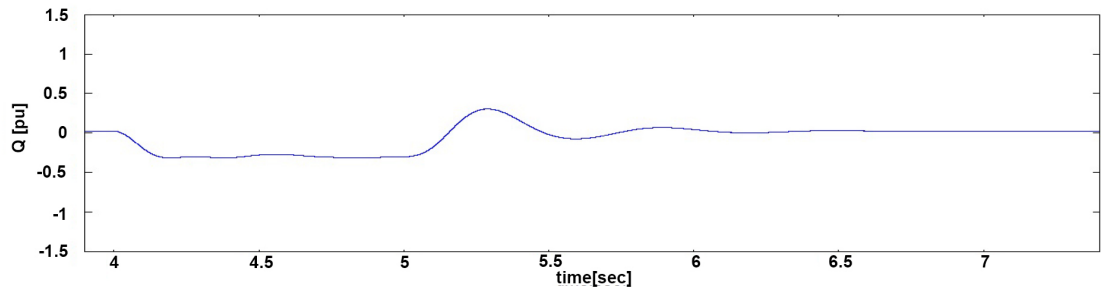

(c) Output reactive power

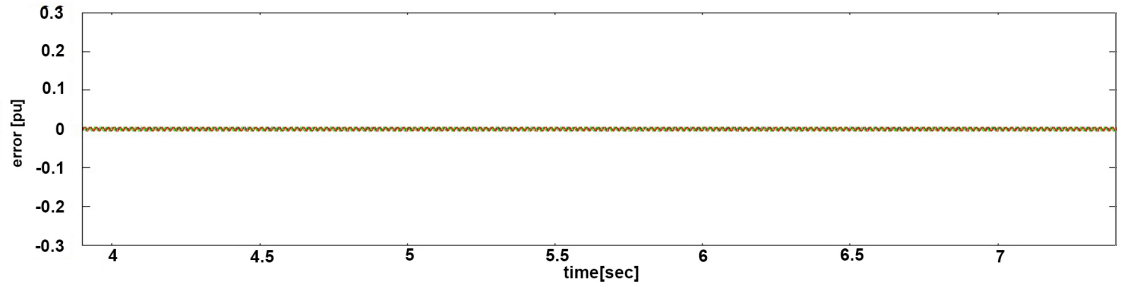

(d) Output current error

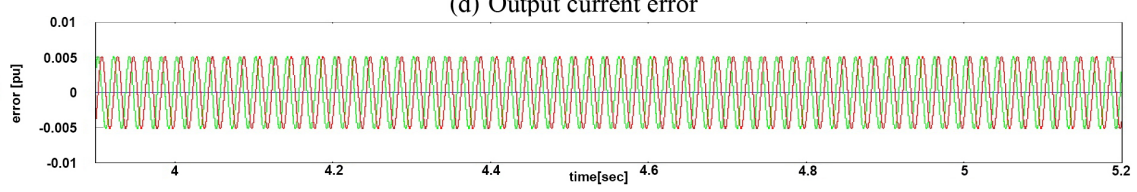

(e) Expanded output current error

(blue line: zero sequence current, green line: positive sequence current, red line: negative sequence current)

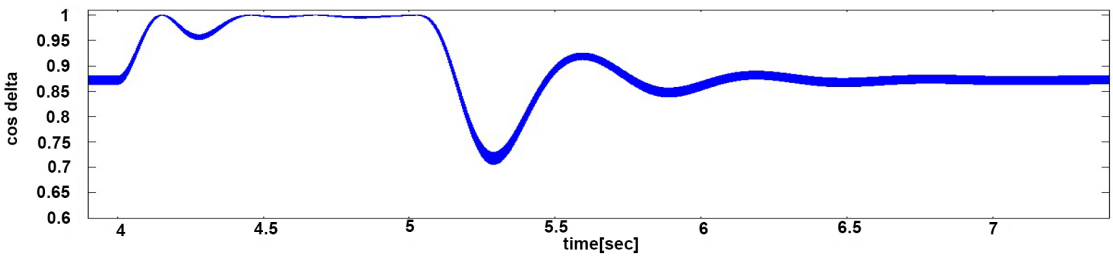

(f) Cosine of internal phase angle

Figure 6. Transient response of the proposed current controller.

proposed method can be expected to be more stable than the conventional method.

The contribution of the proposed method to stability of the grid system depends on performance of the virtual synchronous generator model. In the future, we will verify and improve the robustness against a grid system, and ex- 
amine the effectiveness when connected to the uncertain grid system with a wind power generator.

\section{Acknowledgements}

Supported by JSPS KAKENHI Grant Number JP17K06289.

\section{Conflicts of Interest}

The authors declare no conflicts of interest regarding the publication of this paper.

\section{References}

[1] Masson-Delmotte, V.P., Zhai, H.-O., Portner, D., Roberts, J., Skea, P.R., Shukla, A., Pirani, W., Moufouma-Okia, C., Pean, R., Pidcock, S., Connors, Y., Chen, X., Zhou, M.I., Gomis, E., Lonnoy, T., Maycock, M., Tignor and Waterfield, T. (Eds.) (2018) "Global Warming of 1.5C", the Intergovernmental Panel on Climate Change (IPCC). $630 \mathrm{p}$.

[2] Muyeen, S.M., et al. (Eds.) (2012) Wind Energy Conversion Systems, Technology and Trend. Springer, Berlin. https://doi.org/10.1007/978-1-4471-2201-2

[3] Bevrani, H. (2014) Robust Power Frequency Control. Springer, Berlin, 349-376. https://doi.org/10.1007/978-3-319-07278-4 12

[4] Torres, M. and Lopes, L.A.C. (2013) Virtual Synchronous Generator: A Control Strategy to Improve Dynamic Frequency Control in Autonomous Power Systems. Energy and Power Engineering, 5, 32-33. https://doi.org/10.4236/epe.2013.52A005

[5] Poolla, B.K., Grob, D. and Dorfler, F. (2019) Placement and Implementation of Grid-Forming and Grid-Following Virtual Inertia and Fast Frequency Response. IEEE Transaction on Power Systems, 34, 3035-3046. https://doi.org/10.1109/TPWRS.2019.2892290

[6] Umemura, A., Takahashi, R. and Tamura, J. (2017) Parallel-Connected Two-Generator Model Following Control for Grid-Interconnected Inverter. The 20 th International Conference on Electrical Machines and Systems (ICEMS2017), Sydney, 11-14 August 2017, 6 p. https://doi.org/10.1109/ICEMS.2017.8056460

[7] Umemura, A., Haneyoshi, T., Saito, Y. and Harshima, F. (2007) Discrete-Time Model Following Control of Inverter with Rectifier Load. Electrical Engineering in Japan, 158, 72-81. https://doi.org/10.1002/eej.20375

[8] Furuta, K. and Komiya, K. (1982) Design of Model Following Servo Controller. IEEE Transactions on Automatic Control, 27, 725-727. https://doi.org/10.1109/TAC.1982.1102962 